\title{
The Examination of a Competition Matrix for Transitivity and Intransitive Loops
}

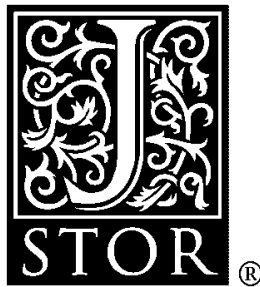

\author{
James B. Grace; Glenn R. Guntenspergen; Janet Keough
}

Oikos, Vol. 68, No. 1. (Oct., 1993), pp. 91-98.

Stable URL:

http://links.jstor.org/sici?sici=0030-1299\%28199310\%2968\%3A1\%3C91\%3ATEOACM\%3E2.0.CO\%3B2-\%23

Oikos is currently published by Nordic Society Oikos.

Your use of the JSTOR archive indicates your acceptance of JSTOR's Terms and Conditions of Use, available at

http://www.jstor.org/about/terms.html. JSTOR's Terms and Conditions of Use provides, in part, that unless you have obtained prior permission, you may not download an entire issue of a journal or multiple copies of articles, and you may use content in the JSTOR archive only for your personal, non-commercial use.

Please contact the publisher regarding any further use of this work. Publisher contact information may be obtained at http://www.jstor.org/journals/oikos.html.

Each copy of any part of a JSTOR transmission must contain the same copyright notice that appears on the screen or printed page of such transmission.

The JSTOR Archive is a trusted digital repository providing for long-term preservation and access to leading academic journals and scholarly literature from around the world. The Archive is supported by libraries, scholarly societies, publishers, and foundations. It is an initiative of JSTOR, a not-for-profit organization with a mission to help the scholarly community take advantage of advances in technology. For more information regarding JSTOR, please contact support@jstor.org. 


\title{
The examination of a competition matrix for transitivity and intransitive loops
}

\author{
James B. Grace, Glenn R. Guntenspergen and Janet Keough
} Grace, J. B., Guntenspergen, G. R. and Keough, J. 1993. The examination of a
competition matrix for transitivity and intransitive loops. - Oikos 68: 91-98.

\begin{abstract}
Recent examinations of competition matrices for transitivity (species A $>$ species B $>$ species C) have used techniques that can be subject to certain biases. First, recent theoretical and empirical analyses have shown that traditional measures of competitive performance are biased in favor of the larger species. It is argued that this size bias has the potential to bias analyses of transitivity. Second, analytical techniques used to test matrices for transitivity can be shown to be insensitive to the presence of intransitive loops. Techniques are presented for exploring both these types of errors and these techniques are illustrated using the results from a six-species study of marsh plants. In addition, two published studies are partially reanalyzed using a technique designed to detect intransitivities. Results for both the new data set as well as for the published data sets fail to reveal intransitivities. For the marsh plant study, the size bias associated with traditional measures of competitive success did not bias in favor of transitivity. We conclude (1) that the studies examined do not possess intransitive loops and (2) care must be taken in order to avoid biased analyses if intransitive loops are to be detected.
\end{abstract}

J. B. Grace, Dept of Botany, Louisiana State Univ., Baton Rouge, LA 70803, USA (present address: National Wetlands Research Center, U.S. Fish and Wildlife Service, 700 Cajundome Blvd, Lafayette, LA 70506, USA). - G. R. Guntenspergen and J. Keough, National Wetlands Research Center, U.S. Fish and Wildlife Service, 700 Cajundome Blvd, Lafayette, LA 70506, USA.

The role of competition in controlling community structure has long been viewed as both important and potentially complex (Begon et al. 1986). Among the many controversies about competition has been the issue of whether there exist intransitive networks amongst competitors (Buss and Jackson 1979, Buss 1980, Aarssen 1989, Keddy and Shipley 1989, Herben and Krahulec 1990, Silvertown and Dale 1991). Intransitivity refers to the situation where competitive interactions are complex and it is not possible to establish a consistent ranking of competitive performance (e.g. species $\mathrm{A}>$ species $B$, species $B>$ species $C$, but species $C>$ species A). In this case there is said to exist a network of competitive performance that can inhibit competitive exclusion. In contrast, transitivity refers to the situation where, if $\mathrm{A}>\mathrm{B}$ and $\mathrm{B}>\mathrm{C}$, then $\mathrm{A}>\mathrm{C}$. For a matrix of competitors, transitivity will mean that the rankings of competitive performance will be independent of the reference species used to generate that ranking and a consistent competitive hierarchy will exist.

Despite earlier examples of intransitive networks from marine systems (Buss and Jackson 1979), analyses of plant communities have indicated that groups of competing species can typically be ranked into transitive hierarchies (Goldsmith 1978, Mitchley and Grubb 1986, Wilson and Keddy 1986, Goldberg and Fleetwood 1987, Miller and Werner 1987, but see Taylor and Aarssen 1990). In their treatment of the subject, Keddy and Shipley (1989) analyzed data from eight published competition experiments with diallel designs (all possible pairs of species). Based on their analyses, they concluded that competitive relations are generally transitive and hypothesized that the primary reason for transitivity was the importance of plant size in competitive 
performance (i.e. rankings of plant competitive performance followed rankings of plant size, particularly height).

Herben and Krahulec (1990) have since pointed out that intransitivities may involve interactions amongst different life stages and have criticized Keddy and Shipley's reliance on experiments that examine only a limited range of possible interactions. In their paper they raise the question of, "How sufficient are the existing experiments for detecting intransitivities?" In a related paper, Silvertown and Dale (1991) have argued that methodological problems with the analyses presented in previous studies invalidate support for transitive hierarchies. In this paper we consider the potential impact of these methodological problems on the evaluation of competition matrices.

\section{Possible sources of error}

One possible bias that could affect analyses of competition matrices has to do with basic limitations of traditional indicators of competitive performance. In their examination of published studies, Keddy and Shipley noted that the experiments examined were of the substitutive type (based on the 'replacement series' of de Wit 1960) and that the traditional analyses of data from this design have been subject to some criticism (Firbank and Watkinson 1985, Connolly 1986). However, what Keddy and Shipley did not note was that one of the less publicized criticisms of the technique they used for analysis is the possibility of bias in favor of larger plants (Connolly 1986, unpubl., Silvertown and Dale 1991). Thus, there exists the possibility that their analyses were actually biased in favor of their conclusions (that larger plants are better competitors).

In a recent evaluation of size bias in the analysis of substitutive experiments (Grace et al. 1992), we examined the potential for traditional indices such as Relative Yields (as used by Keddy and Shipley, and many others) to be biased in favor of larger plants. In this study we utilized a recently proposed, sizeindependent indicator of performance in mixture (the Relative Efficiency Index - Connolly 1987) and found that in this situation, the index appeared to be useful in eliminating size bias. Using data from both a three-year, diallel experiment of six competing marsh species and results from model simulations, we were able to show (1) that Relative Yields (and other traditional measures of competitive success) are inherently biased in favor of the initially larger plants and (2) that this bias is most severe in the early phases of an experiment and decreases over time.

The essential basis for a size bias in substitutive experiments comes from the fact that when a larger species is placed in 50-50 mixture with a smaller species, the larger species experiences an initial reduction in competitive pressure simply due to the smaller size (and, therefore lower space requirements) of the other species. This phenomenon will generate results that suggest the larger species to be the better competitor regardless of the per gram competitive ability. As shown by Grace et al. (1992), if a smaller but more aggressive perennial species is mixed with a larger less aggressive species, traditional analysis will initially show the larger species to be the better competitor despite the fact that the smaller species is slowing driving the larger species to extinction. However, over a sufficiently long period of time (several generations), even traditional analyses will correctly indicate competitive superiority. What the relative efficiency index (Connolly 1987) does is to indicate the direction the mixture is heading from the very beginning.

It can be shown that size bias can not only incorrectly assess competitive performance but can also bias in favor of transitivity using a simple example. Imagine that there exists an intransitive loop in the true competitive performances such that

$\mathrm{A}>\mathrm{B}>\mathrm{C}>\mathrm{A}$.

If a diallel experiment is conducted with all possible combinations of species, it is possible to generate rankings of competitive performance relative to each species. For the above relationship, the following results would be expected:

test species
A
B
A
$\mathrm{C}>\mathrm{A}>\mathrm{B}$
C
$\mathrm{A}>\mathrm{B}>\mathrm{C}$
$\mathrm{B}>\mathrm{C}>\mathrm{A}$.

true competitive ranking

As this example illustrates, intransitive loops generate a particular pattern of rankings for the species in the loop. This pattern is one in which the three species are completely inconsistent in their rankings.

Now, for this example, let the initial plant sizes of the species be

$\mathrm{A}>\mathrm{B}>\mathrm{C}$

and let there exist a bias in the index of competitive performance (such as reported for 'Relative Yields', 'Crowding Coefficients' and 'Aggressivities' by Connolly 1986 and Grace et al. 1992). If the size bias is sufficiently strong relative to the magnitude of differences in true competitive abilities, then we might obtain one of the following sets of ranking:

test observed ranking with observed ranking species partial size bias with full size bias
A
$\mathrm{A}>\mathrm{C}>\mathrm{B}$
B $\quad$ A $>$ B $>$ C
$\mathrm{A}>\mathrm{B}>\mathrm{C}$
$\mathrm{A}>\mathrm{B}>\mathrm{C}$
$\mathrm{B}>\mathrm{A}>\mathrm{C}$
$\mathrm{A}>\mathrm{B}>\mathrm{C}$. 
As can be seen from this example, size bias can have two effects, (1) to make observed patterns of rankings deviate from those expected for intransitive loops and (2) to increase the consistency among rankings. Both effects act to bias in favor of transitivity.

A second possible bias that could affect analyses of competitive networks is essentially the type II error of hypothesis testing, namely, failing to detect an intransitive loop that exists. For the sake of the following discussion, we will assume that we are dealing with sizeindependent measures of competitive performance.

Several possible statistical techniques can be used to examine a matrix of competition coefficients for transitivity, randomness, or intransitivity. Keddy and Shipley (1989) used a technique that counted the observed number of transitive paths of various lengths in a matrix and compared these numbers to those expected by chance in a matrix generated by a null model of random interactions. For 7 of 8 matrices examined, they found significant transitivity. In our analyses, we utilize a somewhat different technique by generating rankings of competitive performance against each species in the matrix (as shown above) and then testing the hypothesis that the rankings are in agreement using Kendall's Test of Concordance Among Rankings (Kendall and Babington-Smith 1939, Daniel 1990). Our choice of Kendall's test in this analysis is based on its simplicity, ready availability, and ease of interpretation. Kendall's test yields a coefficient of concordance that goes from 0 (no similarity among rankings) to 1.0 (complete agreement among rankings). At the time of this writing, the more sophisticated technique of Keddy and Shipley (1989) is not available for general distribution (Shipley pers. comm.).

The above tests are quite adequate if one only wishes to determine if a matrix is generally transitive and nonrandom. However, it can be shown that under certain circumstances, intransitive loops can be hidden by such analyses. As illustrated above, for a simple three-species matrix, an intransitive loop results in rankings that are entirely inconsistent and would be easily detected by any relevant statistical test. However, for matrices of greater size, intransitive loops may be hidden. Take as an example the case of a 6-species matrix where

$$
\mathrm{A}>\mathrm{B}>\mathrm{C}>\mathrm{D}>\mathrm{E}>\mathrm{F}>\mathrm{D} \text {. }
$$

The observed matrix of competitive rankings would be as follows:

test species
A
B
C
D
E
F

competitive ranking

$$
\begin{aligned}
& \mathrm{A}>\mathrm{B}>\mathrm{C}>\mathrm{D}>\mathrm{E}>\mathrm{F} \\
& \mathrm{A}>\mathrm{B}>\mathrm{C}>\mathrm{D}>\mathrm{E}>\mathrm{F} \\
& \mathrm{A}>\mathrm{B}>\mathrm{C}>\mathrm{D}>\mathrm{E}>\mathrm{F} \\
& \mathrm{A}>\mathrm{B}>\mathrm{C}>\mathrm{F}>\mathrm{D}>\mathrm{E} \\
& \mathrm{A}>\mathrm{B}>\mathrm{C}>\mathrm{E}>\mathrm{F} \\
& \mathrm{E}>\mathrm{B}>\mathrm{C}>\mathrm{F}>\mathrm{D}
\end{aligned}
$$

In this example the submatrix contained within the box contains the signature pattern of a loop but the overall matrix is quite ordered. The ranking of the total matrix would likely test as transitive by any of the techniques that have been used. For example, Kendall's index of Concordance gives a value of $\mathrm{W}=0.91$ and the accompanying chi-square value is highly significant. To appreciate how thoroughly hidden this intransitive loop is we should note that a Kendell's W as low as 0.20 would indicate significant concordance $(\mathrm{p}=0.05)$.

It is also important to note that techniques such as those used by Keddy and Shipley (1989) or above do not specifically test for intransitivity. This is not a criticism of their analysis of general transitivity but does represent a lost opportunity to explore intransitivities. Thus, even if a matrix is found to not possess transitivity, that still does not demonstrate intransitivity, but may only result from a weak and inconsistent competitive hierarchy or variable data set.

One final point about sources of error in analyses of matrices can be illustrated by the work of Aarssen (1989). The examinations of competitive matrices by Keddy and Shipley (1989) and in this paper simply ask the non-parametric question about patterns of rankings. Such analyses do not necessarily test for the statistical significance of each inequality in the matrix. Thus, it is quite possible for 'equivalent' competitive performances to be contained within the matrix. Whether such non-significant differences represent true equivalencies or whether they simply represent insufficient statistical power to detect existing differences is a point of potential debate. The unanswered question of competitive equivalence, however, does not invalidate an assessment of overall matrix order. Therefore, in this paper we will follow Keddy and Shipley in examining matrices for the simple rankings of competitive performance.

\section{Techniques to reduce bias}

In order to reduce the biases discussed above we need to (1) employ a technique for measuring competitive performance that is independent of size bias and (2) supplement the existing tests for transitivity with techniques that can detect intransitivity.

\section{Size bias}

Connolly (1987) has recommended a technique for analyzing the behavior of mixtures that is largely independent of bias due to relative plant sizes. What he has proposed is the calculation of a 'Relative Efficiency Index' (REI) for each species in a mixture. The form of this index used here is the difference between relative growth rates of the two species in a mixture, or

$$
\mathrm{REI}=\ln \left(\mathrm{w}_{\mathrm{ia}} / \mathrm{w}_{0 \mathrm{a}}\right)-\ln \left(\mathrm{w}_{\mathrm{ib}} / \mathrm{w}_{0 \mathrm{~b}}\right)
$$


Table 1 . List of 20 possible 3 -species intransitive loops in a $6 \times 6$ matrix of competitors.

\begin{tabular}{|c|c|c|}
\hline $\begin{array}{l}1>2>3>1 \\
1>3>4>1 \\
1>4>5>1 \\
1>5>6>1\end{array}$ & $\begin{array}{l}1>2>4>1 \\
1>3>5>1 \\
1>4>6>1\end{array}$ & $\begin{array}{l}1>2>5>1 \\
1>3>6>1\end{array}$ \\
\hline $\begin{array}{l}2>3>4>2 \\
2>4>5>2 \\
2>5>6>2\end{array}$ & $\begin{array}{l}2>3>5>2 \\
2>4>6>2\end{array}$ & $2>3>6>2$ \\
\hline $\begin{array}{l}3>4>5>3 \\
3>5>6>3\end{array}$ & $3>4>6>3$ & \\
\hline$>5>6>4$ & & \\
\hline
\end{tabular}

where $\mathrm{w}_{\mathrm{ia}}$ refers to the biomass (or indicator of biomass) of species ' $a$ ' at time $i$ and $w_{0 a}$ refers to the biomass of species ' $a$ ' at time zero. It is important to note that this index can be viewed as a refinement of the traditional 'ratio diagram' technique (de Wit 1960) and that these analyses are independent of monoculture performance.

In a previous analysis of measures of competitive performance we have been able to confirm using mechanistic simulation models of competition that the REI index is unbiased by initial plant sizes (Grace et al. 1992). Most importantly, in our analyses this index was consistently accurate in indicating competitive superiority while traditional indicators such as Relative Yields were not. The calculation of REI requires knowledge of the initial size of individuals, a parameter rarely reported in published studies of competition. Thus, in this paper we will be able to use this index to analyze the effect of size bias for our own data but will not be able to examine published competition matrices using this technique.

\section{Detection of intransitive loops}

As discussed above, current techniques for examining matrices do not actually test for intransitive loops. It has also been shown that such loops do not generate random patterns but create a predictable pattern. Thus, what is needed is a specific examination of the matrix for intransitivities. These tests should not be used as a replacement for tests such as the Concordance Test (Kendall) but should accompany such tests.

Consideration of an $\mathrm{n}$-species matrix of competitors can be shown to potentially contain $n ! /(n-3) ! 3$ ! individual, 3-species intransitive loops (Shipley pers. comm.). In the case of six species, the number of loops would be 20 (Table 1). If we consider the possibility that a network of competitors could possess more than one loop, there could exist a great many more loops in a single network. However, only one pattern (absolute agreement among rankings) would unambiguously indicate complete transitivity. Consideration of all possible multi-loop patterns would generate a complex problem for analysis. However, by noting that all multi-loop intransitivities are made up of individual loops, we need only determine if a matrix contains any of the single loops. For matrices of 6 species this involves the inspection of 20 three-species combinations.

Table 1 presents an example of 20 possible single-loop intransitivities for a 6-species matrix. To test for intransitivities it is necessary to examine the matrix for the presence of these 20 loop 'signatures'. We propose that the evaluation of a matrix for intransitivities should be a two-stage process. First, average competitive performances must be calculated to generate an overall ranking of competitors. This overall ranking is then used to generate 20 three-way rankings. It is, of course, possible that these patterns will be seen by chance alone. However, given the fact that finding a single intransitive loop would be a major discovery, we do not wish to deal in such loose probabilities. Rather, we propose that if a match is found between observed 3-way ranking patterns and those patterns predicted for intransitivities, then the data for those three species should be examined independently from the rest of the data matrix for significance. In other words, it would be essential to test the specific hypothesis that those three species constitute an intransitive loop. Only then would the existence of a particular intransitive loop be confirmed.

We feel that this procedure would facilitate our ability to detect intransitive loops in competition matrices. However, we do not believe that our proposed technique is perfect. The probability of finding a biologically meaningful intransitive loop by surveying matrices is likely to be low since such interactions are expected to involve particular biological circumstances not usually found in a controlled standardized experiment (see Herben and Krahulec 1990). Nonetheless, unexpected results encountered in a matrix of competitors might lead to a hypothesis about a particular intransitivity that could be subject to further experimental tests. Thus, we believe that competitive matrices should not just be tested for general transitivity but should also be examined specifically for intransitive loops.

In the current paper, we examine a six-species diallel experiment for transitivity and intransitive loops. Further, we examine the effects of the size bias in traditional measures of competitive success on the detection of transitivity. Finally, we reexamine two published matrices for intransitive loops.

\section{Methods}

\section{Diallel experiment of marsh species}

To assess relative competitive performance, plants were allowed to compete in a diallel experiment (all possible species combinations) by using a substitutive ('replace- 
Table 2. Competitive rankings and tests of transitivity based on Relative Yields. Transitivity was tested by using Kendall's Coefficient of Concordance (W) which tests for the correlation among rankings (Daniel 1990). All years were found to have highly significant correlations among rankings based on the different species. Numerical codes for each species are $1=$ Sagittaria, $2=$ Eleocharis, $3=$ Solidago, $4=$ Scirpus validus, $5=$ Scirpus robustus, $6=$ Spartina .

\begin{tabular}{lcc}
\hline Year & Species & Rankings \\
\hline 1 & 1 & $4>2>1>5>3>6$ \\
& 2 & $4>2>1>3>6>5$ \\
3 & $4>1>5>2>6>3$ \\
4 & $2>4>1>5>3>6$ \\
5 & $2>4>1>5>3>6$ \\
6 & $1>4>2>5>3>6$
\end{tabular}

2

$\begin{array}{ll}1 & 2>5>1>4>3>6 \\ 2 & 2>4>5>3>6>1 \\ 3 & 4>2>5>6>1>3 \\ 4 & 2>5>4>1>6>3 \\ 5 & 2>4>5>6>3>1 \\ 6 & 4>5>2>1>6>3\end{array}$

23.57

0.01

3

$\begin{array}{ll}1 & 5>2>4>3>1>6 \\ 2 & 2>4>5>3>6>1 \\ 3 & 5>2>4>6>3>1 \\ 4 & 2>4>5>1>3>6 \\ 5 & 4>2>5>3>6>1 \\ 6 & 4>5>2>1>6>3\end{array}$

$0.78 \quad 23.52 \quad 0.01$

ment-series') design (de Wit 1960). Containers of plants were arranged in a random block design with one replicate of each treatment per block and 12 replicate blocks. Containers were 1-1 solid plastic pots without drain holes and transplanted ramets were at a total density of 2 per pot (see Grace et al. 1992 for further details on our protocol). The soil used in the experiment was collected from a marsh adjacent to the Tchefuncte River in St. Tammany Parish, Louisiana, USA. Soil was collected from beneath the upper $20 \mathrm{~cm}$ of the root mat. Before planting, roots and rhizomes were removed by passing the sediment through a $1-\mathrm{cm}$ mesh screen. In addition, the soil was allowed to aerate until hydrogen sulfide could no longer be detected. Soil characteristics were determined by the Soil Testing Laboratory at Louisiana State Univ. using standard methods (Moore and Chapman 1986). The soil was a histosol with an average organic content of $44 \%$, a mineral fraction dominated by clays, and a $\mathrm{pH}$ of $6.1-6.3$.

Transplants of the six species were also collected from the marsh adjacent to the Tchefuncte River during February 1988. To minimize historical differences between species, transplants were allowed to grow for about 1 month in small $\left(150-\mathrm{cm}^{3}\right)$ containers of homogenized wetland sediment prior to use in the experiment. Further, at the initiation of the experiment, transplants were removed from the preconditioning containers, washed, blotted dry, and measured for fresh weight.
Ten additional transplants were used to determine the fresh/dry mass ratio. This information was used to estimate dry mass values for initial propagules. In addition, initial shoot lengths of all shoots in a pot were determined for each species for use in non-destructive evaluation of performance over time.

Planting took place in April 1988 and the experiment was allowed to proceed for three growing seasons. Pots were maintained in a flooded condition throughout the experiment. As a non-destructive estimate of biomass, the total length of all shoots in a pot were measured near the end of the growing season for southern Louisiana $(10 / 88,11 / 89)$ and at the time of final harvest (7/90). Before the final harvest, examination of the non-destructive data showed a strong consistency with similar measurements from the previous year; thereby justifying the early harvesting in 1990 . Dry biomass data from the final harvest were examined and found to confirm the reliability of total shoot length as an indicator of mass. Perhaps because of the simple, graminoid morphology of the species studied, regression analysis showed that total shoot length was linearly correlated with shoot biomass (in contrast to the more complex relationships that occur for some species, Grace 1985). In this study, we found the correlation between total shoot height and shoot biomass to be as follows: Spartina patens $-\mathrm{R}^{2}=0.84$, Scirpus robustus $\mathrm{R}^{2}=0.83$, Scirpus validus $-\mathrm{R}^{2}=0.75$, Solidago sempervirens $-\mathrm{R}^{2}=0.67$, Eleocharis macrostachya $-\mathrm{R}^{2}=$ 0.88 , and Sagittaria lancifolia $-\mathrm{R}^{2}=0.69$.

\section{Data analyses}

For analysis as a substitutive experiment, relative yields (RYs) were calculated for each species by dividing mixture performance by monoculture performance. For a size-independent comparison, the data were also analyzed using the 'Relative Efficiency Index' (REI) for each species pair (Connolly 1987 - defined above). Since the design consisted of 1 replicate of each treatment per block, RYs and REIs were calculated independently for each block yielding an unbiased estimate of the variance of these derived variables. So as to focus on the potential to bias conclusions about competitive performance, the data (either RYs or REIs) were used to determine the rankings of competitors. Statistical analyses of the rankings were performed using Kendall's Test of Concordance (Daniel 1990) which provides a measure of the degree to which a set of rankings are in agreement. This procedure was used to test the hypothesis that the hierarchical ranking of species was consistent throughout the matrix and, therefore, that a transitive hierarchy existed. Values of $\mathrm{W}$ range from 0 (no relationship between rankings) to 1.0 (complete agreement among rankings). Matrices were also examined for intransitive loops using the method described in the previous section. 
Table 3. Competitive rankings and tests of transitivity based on Relative Efficiency Index values. Tests are described in Table 2.

\begin{tabular}{|c|c|c|c|c|c|}
\hline Year & Species & Rankings & W & Chi-square & $\mathrm{P}<$ \\
\hline 1 & $\begin{array}{l}1 \\
2 \\
3 \\
4 \\
5 \\
6\end{array}$ & $\begin{array}{l}2>4>5>6>3>1 \\
2>4>6>5>3>1 \\
4>2>5>6>3>1 \\
2>4>5>6>1>3 \\
2>4>5>6>1>3 \\
4>2>5>6>3=1\end{array}$ & 0.93 & 27.92 & 0.01 \\
\hline 2 & $\begin{array}{l}1 \\
2 \\
3 \\
4 \\
5 \\
6\end{array}$ & $\begin{array}{l}2>5>4>1>3>6 \\
2>4>6>5>3>1 \\
2>4>6>5>1>3 \\
2>4>1>5>6>3 \\
2>4>5>6>3>1 \\
4>2>5>1>6>3\end{array}$ & 0.79 & 23.61 & 0.01 \\
\hline 3 & $\begin{array}{l}1 \\
2 \\
3 \\
4 \\
5 \\
6\end{array}$ & $\begin{array}{l}2>4>5>6>1>3 \\
2>4>5>6>1>3 \\
2>4>5>6>1>3 \\
2>4>1>5>3>6 \\
2>4>5>1>6>3 \\
4>2>5>6>1>3\end{array}$ & 0.90 & 27.04 & 0.01 \\
\hline
\end{tabular}

Two published matrices are analyzed for intransitive loops using the technique proposed in this paper. The studies reexamined are a diallel study of seven grassland species by Mitchley and Grubb (1986) and diallel study of six lakeshore species by Wilson and Keddy (1986). Both studies provide sufficient data to generate a matrix of rankings that can be examined for intransitive loops. At the same time, both matrices are sufficiently large for such loops to be hidden from conventional analysis.

\section{Results}

\section{Effects of size bias on transitivity of marsh species experiment}

When Relative Yields (RYs) were used to generate rankings, it was found that the rankings generated relative to each test species were very similar (Table 2). Concordance values ranged from 0.78 to 0.81 where a value of 1.0 equals perfect agreement. In this data set a $\mathrm{W}$ value as low as 0.20 would indicate a significant concordance among rankings at $p=0.05$. Thus, these analyses indicate a high degree of consistency.

Analysis of the results in terms of REI values (Table 3) also showed strong concordance. In this case, W values varied from 0.93 to 0.79 indicating a concordance among rankings at least as strong as found for RY values. Again, values were high indicating an extremely high degree of concordance.

Comparison between rankings based on RYs and REIs shows that the rankings are not in complete agree- ment. In fact, previous analyses found that the two indices were in disagreement for years 1 and 2, and were only correlated in year 3 . This lack of agreement between indices results from size bias in the RY analysis. Despite this effect, both indices showed rankings to be highly transitive.

\section{Examination of matrices for intransitive loops}

Examination of the matrices for the six marsh species, as well as the matrices published by Mitchley and Grubb (1986) and Wilson and Keddy (1986), failed to reveal any matches with the rankings expected for intransitive loops (Table 4). As shown by the values of Kendall's W (Table 4), concordance among rankings was lower for the study by Wilson and Keddy (1986) than for the other studies. This greater variability was reflected in a considerable inconsistency amongst rankings. However, none of the $3 \times 3$ matrices matched those predicted for intransitive loops.

\section{Discussion}

Grace et al. (1992) have previously shown that traditional analyses of substitutive experiments (such as Relative Yields or Relative Crowding Coefficients) are inherently biased in favor of initially larger plants and that this bias is eventually lost (in our case, after two years). In these analyses it was found that initial plant size was partially correlated with RYs. It was also found that REI values were not correlated with plant size, either initial or final. Thus, true competitive performance was not size-dependent.

We believe that it is hypothetically possible for sizeeffects on indices of competitive performance to bias in favor of hierarchies if the bias effect is sufficiently strong. In our study of six marsh species, however, there was no evidence of bias towards transitivity in rankings based on traditional indicators. Rankings based on RYs were highly consistent, but rankings

Table 4. Tests for transitivity and intransitive loops. Kendall's test was for the complete matrix while possible loops were checked using $3 \times 3$ matrices as shown in Table 1 . Kendall's values for each year of our study are repeated from Table 3 to facilitate comparisons among studies.

\begin{tabular}{lcc}
\hline Data considered & $\begin{array}{c}\text { Kendall's W } \\
(\mathrm{p}<)\end{array}$ & $\begin{array}{c}\text { Number of } \\
\text { loops }\end{array}$ \\
\hline Our study - year 1 & $0.93(0.01)$ & 0 \\
Our study - year 2 & $0.79(0.01)$ & 0 \\
Our study - year 3 & $0.90(0.01)$ & 0 \\
Mitchley and Grubb (1986) & $0.88(0.01)$ & 0 \\
Wilson and Keddy (1986) & $0.54(0.01)$ & 0 \\
\hline
\end{tabular}


Table 5. Hypothetical example of how size-bias in traditional measures of competitive performance could affect the consistency amongst rankings. In this example, there exists an intransitive network where $\mathrm{A}>\mathrm{B}>\mathrm{C}>\mathrm{A}$. In addition, species $A$ has the largest individuals and species $C$ has the smallest.

\begin{tabular}{lll}
\hline $\begin{array}{l}\text { Test } \\
\text { species }\end{array}$ & $\begin{array}{c}\text { True competitive } \\
\text { performance }\end{array}$ & $\begin{array}{c}\text { Size-biased competitive } \\
\text { performance }\end{array}$ \\
\hline & $\mathrm{C}>\mathrm{A}>\mathrm{B}$ & $\mathrm{A}>\mathrm{B}>\mathrm{C}$ \\
$\mathrm{B}$ & $\mathrm{A}>\mathrm{B}>\mathrm{C}$ & $\mathrm{A}>\mathrm{B}>\mathrm{C}$ \\
$\mathrm{C}$ & $\mathrm{B}>\mathrm{C}>\mathrm{A}$ & $\mathrm{A}>\mathrm{B}>\mathrm{C}$ \\
\hline
\end{tabular}

based on REIs were even more consistent suggesting that in this case, if there was any effect the size bias in traditional analyses acted to obscure rather than exaggerate transitivity. It should be noted that in this data set true competitive performance (as indicated by REI values) did not correlate with size. Based on these findings, we conclude that size-bias in traditional indices such as RYs did not bias evaluations of transitivity in our study.

Of course, the absence of bias in our study is no guarantee that the analyses performed by Keddy and Shipley were unbiased. As shown by the hypothetical example presented in Table 5, it is possible for traditional indices (such as used by Keddy and Shipley) to inaccurately indicate transitivity (see also arguments by Silvertown and Dale 1991). In their paper they found that plant size was well correlated with competitive success, suggesting the potential for an exaggeration of transitivity. There are at least three ways in which plant size can influence traditional measures of competitive performance. First, measures of competitive performance such as RYs are very sensitive to initial differences in plant size. Second, plants with more rapid initial growth rates during the density-independent phase of growth are likely to be favored by the analysis. Finally, final plant size may have an effect under certain conditions of density and mortality. Due to the complex manner in which plant size might affect competitive performance, the only way in which bias effects can be evaluated is to reanalyze the data using size-insensitive indices such as the Relative Efficiency Index. To perform such an analysis it is necessary to have estimates of initial plant mass.

The tests for transitivity presented here, and the path analyses presented by Keddy and Shipley, do not eliminate the possibility of intransitive interactions. While the intransitive case of $\mathrm{A}>\mathrm{B}>\mathrm{C}>\mathrm{A}$ will be clearly indicated by any analysis technique (Table 5), for a more subtle case such as shown earlier in this paper, general tests for transitivity will fail to determine if intransitive loops are present. Rather, what these tests indicate are that the interactions are predominantly transitive. In a subtle case of intransitivity such as

$$
\mathrm{A}>\mathrm{B}>\mathrm{C}>\mathrm{D}>\mathrm{E}>\mathrm{F}>\mathrm{D}
$$

tests of concordance for a 6-species matrix would yield a value of 0.91 for Kendall's W ( $<<0.001)$. For a more blatant loop in a 7 -species matrix such as

$$
\mathrm{A}>\mathrm{B}>\mathrm{C}>\mathrm{D}>\mathrm{E}>\mathrm{F}>\mathrm{G}>\mathrm{A}
$$

we obtain a concordance of $\mathrm{W}=0.65$ which is higher than that found for the 7-species study of Wilson and Keddy (1986). For the Wilson and Keddy study, however, the weak concordance appears to result from variability in the data rather than from intransitivity. Thus, as shown by these examples, tests for general transitivity are quite insensitive to intransitive loops.

While tests for transitivity may not be good tests for intransitive loops, inspection of the matrices for such loops revealed none. This result greatly increases our confidence that intransitive loops are not present in these studies. Of course it is still possible for a type II error to occur even if matrices are inspected for intransitive loops. Nonetheless, use of the technique presented in this paper should substantially improve our ability to detect loops.

In addition to statistical issues, there are other possible concerns about the conclusions drawn by Keddy and Shipley. As Herben and Krahulec (1990) have pointed out, competitive networks may depend on particular interactions between different life stages of competing species. For example, even if species $\mathrm{A}$ is a better competitor in adult-adult interactions it may still be possible for species B adults to outcompete species A juveniles. Further, relative competitive abilities may shift with life stage (Grace 1985). While it is uncertain if such interactions lead to stable coexistence, they can definitely contribute to non-equilibrium coexistence (e.g. Platt and Weis 1985, Aarssen 1989). Many, if not most competition experiments, fail to examine the complete range of interactions possible and Herben and Krahulec (1990) have argued that data from such experiments are not complete tests of transitivity. While Herben and Krahulec single out de Wit's (1960) 'replacement-series' experiments as inadequate for testing transitivity, their criticisms are equally applicable to the majority of experimental approaches, substitutive or additive, greenhouse or field, unless such approaches include a full range of possible interactions. Although we do not agree with their conclusions that data from substitutive experiments are completely unsuitable for examining transitivity, we do agree that such tests (including our own) are less than complete. As always in science, the absence of evidence for a phenomenon does not necessarily mean it doesn't exist.

To our knowledge, there are no conclusive examples of intransitive competitive loops between species in plant communities and the only example of any sort of intransitivity is presented for competing genotypes by Taylor and Aarssen (1990). In light of this, the conclusion that matrices are generally transitive is not surprising. While examination of diallel experiments for in- 
transitive loops is useful, the discovery of such relationships will require the testing of specific hypotheses based on our knowledge of the complex interactions amongst species. In any such tests, it will be imperative to avoid analytical techniques that are size-biased or insensitive to intransitive loops.

Acknowledgements - We have many people to thank for assistance with this project, especially J. Blasiak, D. Steller, and K. Teague. Statistical advice was provided by B. Moser of the Dept of Experimental Statistics. We also wish to express our appreciation to the following for help: R. Howard, L. Johnson, S. Langevin, M. McAuley, W. Norling, M. Rankin, and K. Taylor. Thanks also to L. Gough, and K. Taylor for review of the manuscript and G. Farris for editorial advice. J. Connolly, B. Shipley, and L. Aarssen offered a number of helpful suggestions that improved the manuscript considerably. Greenhouse facilities were graciously provided by the U.S. Dept of Agriculture's Field Station at Louisiana State Univ. and by the Botany Dept. This research was support by grants from the National Science Foundation and the U.S. Fish and Wildlife Service.

\section{References}

Aarssen, L. W. 1989. Competitive ability and species coexistence: a 'plants-eye view'. - Oikos 56: 386-401.

Begon, M., Harper, J. L. and Townsend, C. R. 1986. Ecology. - Sinauer, Sunderland, MA.

Buss, L. W. 1980. Competitive intransitivity and size-frequency distributions of interacting populations. - Proc. Natl. Acad. Sci. USA 77: 5355-5359.

- and Jackson, J. B. C. 1979. Competitive networks: nontransitive competitive relationships in cryptic coral reef environments. - Am. Nat. 113: 223-234.

Connolly, J. 1986. On difficulties with replacement-series methodology in mixture experiments. - J. Appl. Ecol. 23: 125-137.

- 1987. On the use of response models in mixture experiments. - Oecologia 72: 95-103.

Daniel, W. W. 1990. Applied nonparametric statistics. - PWSKent Publ., Boston.

de Wit, C. T. 1960. On competition. - Versl. Landbouwk. Onderz. 66: 1-82.
Firbank, L. G. and Watkinson, A. R. 1985. On the analysis of competition within two-species mixtures of plants. - J. Appl. Ecol. 22: 503-517.

Goldberg, D. E. and Fleetwood, L. 1987. Competitive effect and response in four annual plants. - J. Ecol. 75: 1131-1144.

Goldsmith, F. B. 1978. Interaction (competition) studies as a step towards the synthesis of sea-cliff vegetation. - J. Ecol. 66: 921-931.

Grace, J. B. 1985. Juvenile versus adult competitive ability in plants: size-dependence in cattails (Typha). - Ecology 66: 1630-1638.

- , Keough, J. and Gutenspergen, G. R. 1992. Size bias in traditional analyses of substitutive competition experiments. - Oecologia 90: 429-434.

Herben, T. and F. Krahulec. 1990. Competitive hierarchies, reversals of rank order and the de Wit approach: are they compatible? - Oikos 58: 254-265.

Keddy, P. A. and Shipley, B. 1989. Competitive hierarchies in herbaceous plant communities. - Oikos 54: 234-241.

Kendall, M. G. and Babington-Smith, B. 1939. The problem of m/rankings. - Ann. Math. Statist. 10: 275-287.

Miller, T.E. and Werner, P.A. 1987. Competitive effects and responses between plant species in a first-year old field community. - Ecology 68:1201-1210.

Mitchley, J. and Grubb, J. P. 1986. The control of relative abundance of perennials in chalk grassland in southern England. I. Constancy of rank order and results of pot and field experiments on the role of interference. - J. Ecol. 74: 1139-1166.

Moore, P. D. and Chapman, S. B. 1986. Methods in plant ecology. - Blackwell, New York.

Platt, W. J. and Weis, I.M. 1985. An experimental study of competition among fugitive prairie plants. - Ecology 66: 708-720.

Silvertown, J. and Dale P. 1991. Competitive hierarchies and the structure of herbaceous plant communities. - Oikos 61:441-444.

Taylor, D. R. and Aarssen, L. W. 1990. Complex competitive relationships among genotypes of three perennial grasses: implications for species coexistence. - Am. Nat. 136: 305-327.

Wilson, S. D. and Keddy, P. A. 1986. Species competitive ability and position along a natural stress/disturbance gradient. - Ecology 67: 1236-1242. 
http://www.jstor.org

\title{
LINKED CITATIONS
}

\author{
- Page 1 of 3 -
}

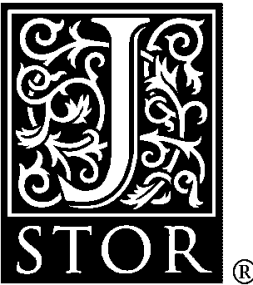

You have printed the following article:

The Examination of a Competition Matrix for Transitivity and Intransitive Loops James B. Grace; Glenn R. Guntenspergen; Janet Keough

Oikos, Vol. 68, No. 1. (Oct., 1993), pp. 91-98.

Stable URL:

http://links.jstor.org/sici?sici=0030-1299\%28199310\%2968\%3A1\%3C91\%3ATEOACM\%3E2.0.CO\%3B2-\%23

This article references the following linked citations. If you are trying to access articles from an off-campus location, you may be required to first logon via your library web site to access JSTOR. Please visit your library's website or contact a librarian to learn about options for remote access to JSTOR.

\section{References}

\section{Competitive Intransitivity and Size-Frequency Distributions of Interacting Populations}

L. W. Buss

Proceedings of the National Academy of Sciences of the United States of America, Vol. 77, No. 9, [Part 2: Biological Sciences]. (Sep., 1980), pp. 5355-5359.

Stable URL:

http://links.jstor.org/sici?sici=0027-8424\%28198009\%2977\%3A9\%3C5355\%3ACIASDO\%3E2.0.CO\%3B2-4

\section{Competitive Networks: Nontransitive Competitive Relationships in Cryptic Coral Reef Environments}

L. W. Buss; J. B. C. Jackson

The American Naturalist, Vol. 113, No. 2. (Feb., 1979), pp. 223-234.

Stable URL:

http://links.jstor.org/sici?sici=0003-0147\%28197902\%29113\%3A2\%3C223\%3ACNNCRI\%3E2.0.CO\%3B2-B

\section{Competitive Effect and Response in Four Annual Plants}

Deborah E. Goldberg; Linda Fleetwood

The Journal of Ecology, Vol. 75, No. 4. (Dec., 1987), pp. 1131-1143.

Stable URL:

http://links.jstor.org/sici?sici=0022-0477\%28198712\%2975\%3A4\%3C1131\%3ACEARIF\%3E2.0.CO\%3B2-8 
http://www.jstor.org

\title{
LINKED CITATIONS
}

\author{
- Page 2 of 3 -
}

Interaction (Competition) Studies as a Step Towards the Synthesis of Sea- Cliff Vegetation F. B. Goldsmith

The Journal of Ecology, Vol. 66, No. 3. (Nov., 1978), pp. 921-931.

Stable URL:

http://links.jstor.org/sici?sici=0022-0477\%28197811\%2966\%3A3\%3C921\%3AI\%28SAAS\%3E2.0.CO\%3B2-C

Juveniles vs. Adult Competitive Abilities in Plants: Size-dependence in Cattails (Typha)

James B. Grace

Ecology, Vol. 66, No. 5. (Oct., 1985), pp. 1630-1638.

Stable URL:

http://links.jstor.org/sici?sici=0012-9658\%28198510\%2966\%3A5\%3C1630\%3AJVACAI\%3E2.0.CO\%3B2-D

Competitive Effects and Responses Between Plant Species in a First-Year Old-Field

Community

T. E. Miller; P. A. Werner

Ecology, Vol. 68, No. 5. (Oct., 1987), pp. 1201-1210.

Stable URL:

http://links.jstor.org//sici?sici=0012-9658\%28198710\%2968\%3A5\%3C1201\%3ACEARBP\%3E2.0.CO\%3B2-8

Control of Relative Abundance of Perennials in Chalk Grassland in Southern England: I. Constancy of Rank Order and Results of Pot- and Field- Experiments on the Role of Interference

J. Mitchley; P. J. Grubb

The Journal of Ecology, Vol. 74, No. 4. (Dec., 1986), pp. 1139-1166.

Stable URL:

http://links.jstor.org/sici?sici=0022-0477\%28198612\%2974\%3A4\%3C1139\%3ACORAOP\%3E2.0.CO\%3B2-9

An Experimental Study of Competition among Fugitive Prairie Plants

William J. Platt; I. Michael Weis

Ecology, Vol. 66, No. 3. (Jun., 1985), pp. 708-720.

Stable URL:

http://links.jstor.org/sici?sici=0012-9658\%28198506\%2966\%3A3\%3C708\%3AAESOCA\%3E2.0.CO\%3B2-V 
http://www.jstor.org

\section{LINKED CITATIONS \\ - Page 3 of 3 -}

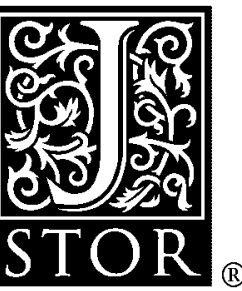

Complex Competitive Relationships Among Genotypes of Three Perennial Grasses: Implications for Species Coexistence

Douglas R. Taylor; Lonnie W. Aarssen

The American Naturalist, Vol. 136, No. 3. (Sep., 1990), pp. 305-327.

Stable URL:

http://links.jstor.org/sici?sici=0003-0147\%28199009\%29136\%3A3\%3C305\%3ACCRAGO\%3E2.0.CO\%3B2-S

Species Competitive Ability and Position Along a Natural Stress/Disturbance Gradient

Scott D. Wilson; Paul A. Keddy

Ecology, Vol. 67, No. 5. (Oct., 1986), pp. 1236-1242.

Stable URL:

http://links.jstor.org/sici?sici=0012-9658\%28198610\%2967\%3A5\%3C1236\%3ASCAAPA\%3E2.0.CO\%3B2-X 